\title{
Consultoria ontopsicológica: o processo de metanoia do líder, do âmbito individual ao âmbito empresarial
}

\author{
Vera Lúcia Rodegheri \\ André Carvalho de Fraga
}

\begin{abstract}
Resumo: Neste artigo, propõe-se analisar as contribuições da consultoria ontopsicológica nas esferas pessoal, familiar e empresarial. Especificamente, objetivou-se identificar fatos, contextos e passagens da vida pregressa que marcaram o processo de metanoia do autorpesquisador, analisar as narrativas selecionadas à luz do conhecimento da ciência ontopsicológica e apontar as contribuições da consultoria ontopsicológica, principalmente no campo empresarial. $\mathrm{O}$ estudo, de natureza narrativa autobiográfica, refere-se à vida do autor-pesquisador, empresário, sócio-fundador de empresas de diversos ramos. Para o enquadramento teórico, utilizaram-se autores contemporâneos e, principalmente, as obras de Antonio Meneghetti. Constatou-se que a consultoria empresarial ontopsicológica distingue-se das demais abordagens, tendo em vista que atua na unidade base do homem e não somente nas esferas operacionais da empresa.
\end{abstract}

Palavras-chave: Consultoria empresarial; Liderança empresarial; Nexo ontológico.

Ontopsychological consultancy: the process of metanoia of the leader, from the individual to the business scope

\begin{abstract}
In this article, it is proposed to analyze the contributions of ontopsychological consulting in the personal, family and business spheres. Specifically, the objective was to identify facts, contexts and passages of previous life that marked the author-researcher's metanoia process, to analyze the selected narratives in light of the knowledge of ontopsychological science and to point out the contributions of ontopsychological consulting, especially in the business field. The study, of an autobiographical narrative nature, refers to the life of the author-researcher, entrepreneur, founding partner of companies of various branches. For the theoretical framework, contemporary authors and, mainly, the works of Antonio Meneghetti were used. It was observed that the ontopsychological business consultancy differs from other approaches, considering that it acts in the basic unit of man and not only in the operational spheres of the company.
\end{abstract}

Consultoria ontopsicológica: el proceso de metanoia del líder, del ámbito individual al ámbito empresarial

Resumen: En este artículo, se objetiva analizar las contribuciones de la consultoría ontopsicológica en el ámbito personal, familiar y empresarial. Específicamente, el objetivo fue identificar hechos, contextos y pasajes de la vida anterior que marcaron el proceso de metanoia del investigador, analizar las narrativas seleccionadas a la luz del conocimiento de la ciencia Ontopsicológica y señalar las contribuciones de la consultoría Ontopsicológica, principalmente en el campo empresarial. El estudio, de carácter narrativo autobiográfico, se refiere a la vida del autor-investigador, empresario, socio fundador de empresas de diversas ramas. Para el marco teórico se utilizaron autores contemporáneos y, principalmente, las obras de Antonio Meneghetti. Se observó que la consultoría empresarial ontopsicológica se difiere de otros enfoques, considerando que actúa en la unidad básica del hombre y no solo en las esferas operativas de la empresa.

Palabras clave: Consultoría de negocios; Liderazgo empresarial; Nexo ontológico.

\section{Introdução}


A ciência ontopsicológica desenvolveu, nos últimos 40 anos, instrumentos que permitem evidenciar o projeto ôntico do ser humano. Esses instrumentos e descobertas confirmam a hipótese racional, cuja estrada, em Filosofia, foi aberta por Edmund Husserl, com a descoberta do "mundo da vida". Os instrumentos da escola ontopsicológica complementam os conhecimentos técnicos e acadêmicos existentes na contemporaneidade, com o diferencial de que, com o método ontopsicológico, é possível individuar, empiricamente, a presença do nexo ontológico no processo de escolha otimal do sujeito. Com os instrumentos da escola ontopsicológica, é possível isolar a ética otimal circunstancial, mas também distinguir as heurísticas desviantes e que impedem a sua percepção reversível com o real (MENEGHETTI, 2014; 2015; VIDOR, 2013).

A necessidade do abandono de estereótipos previamente estabelecidos, para uma constituição individual e livre da moral pré-estabelecida, é necessária ao exercício da liderança. Nesse processo, a consultoria ontopsicológica assume um papel fundamental, porque "[...] possibilita uma revolução na metodologia de consultoria empresarial" (PETRY, 2015, p. 63). Segundo a autora, a consultoria é uma área de interface interdisciplinar, porque envolve conhecimentos das áreas da Administração, Economia, Direito, Sociologia, Política. Quanto à etimologia, "a palavra consultoria deriva do latim consultare e significa dar ou receber conselhos" (PETRY, 2015, p. 63).

Entretanto, a consultoria ontopsicológica distingue-se da abordagem tradicional de consultoria empresarial, porque não atua somente nas esferas operacionais relativas aos processos empresariais (custos, vendas, etc.), mas onde todo processo empresarial tem início: a unidade base homem (MENEGHETTI, 2010a). Em vista disso, evidenciou-se a possibilidade de analisar narrativas de vida do autor-pesquisador ${ }^{1}$ deste estudo, um empresário que, há mais de uma década, segue a consultoria ontopsicológica. Assim, o problema de pesquisa que se busca responder é: quais as contribuições da consultoria ontopsicológica na compreensão e superação de aspectos relativos às esferas pessoal, familiar e empresarial do autor-pesquisador?

A motivação que desencadeou a escrita desse manuscrito está relacionada aos resultados alcançados pelo autor-pesquisador a partir da compreensão sobre como se estrutura a dinâmica psíquica desde a infância e que, depois, traduz-se em comportamentos pouco funcionais. Por decorrência da consultoria ontopsicológica, há a impostação de um novo modo de agir com a família e com a empresa, fundado em um critério inconsciente que perpassa toda a fenomenologia do indivíduo, o Em Si ôntico. Acredita-se que as narrativas,

\footnotetext{
${ }^{1}$ Autor-pesquisador, termo utilizado pela pesquisadora francesa, Marie-Christine Josso (2004).
} 
apresentadas em primeira pessoa, possam servir a outras pessoas, contribuindo com a disseminação do conhecimento ontopsicológico aplicado, principalmente, na área empresarial. Portanto, tem-se, como objetivo geral, analisar as contribuições da consultoria ontopsicológica nas esferas pessoal, familiar e de liderança empresarial do autor-pesquisador. Especificamente, identificam-se fatos, contextos e passagens da vida pregressa que marcaram o processo de metanoia do autor-pesquisador; analisam-se as narrativas selecionadas à luz do conhecimento da ciência ontopsicológica e apontam-se as contribuições da consultoria ontopsicológica, principalmente, no campo empresarial.

A pesquisa é de natureza autobiográfica e a análise fundamenta-se nos conhecimentos da ciência ontopsicológica. Ressalta-se que, na busca realizada, foram localizados estudos de natureza autobiográfica, com análise ontopsicológica, desenvolvidos por Ceratti e Rodegheri (2016) e por Speroto (2017), em que ambos enfatizam a consultoria ontopsicológica na área empresarial. O primeiro refere-se ao processo de formação do líder na gestão de uma empresa, a qual atua na produção e comercialização de sementes de arroz no estado do Rio Grande do Sul. O segundo artigo refere-se ao relato da autora-pesquisadora relativo à superação de estereótipos femininos e à impostação de um novo modo de agir da mulher, a fim de conquistar a própria autonomia econômica e a liderança social.

Quanto à estrutura do texto, a partir desta introdução, descreve-se o referencial teórico-metodológico do estudo. Na sequência, o texto está organizado em três seções interrelacionadas e complementares, denominadas: (I) antecedentes históricos; (II) entrevistas com o Acadêmico Professor Antonio Meneghetti; e (III) discussão do estudo. As considerações finais, também em primeira pessoa, e a lista de referências encerram o manuscrito.

\section{Fundamentação Teórica}

\subsection{Referencial Teórico-Metodológico}

O referencial teórico-metodológico de muitas pesquisas realizadas, ainda hoje, decorre da crença de uma suposta objetividade dos procedimentos de pesquisa, capazes de conferir confiabilidade e autoridade, sem levar em conta a pessoa do pesquisador, isto é, a subjetividade do pesquisador é excluída do campo investigativo, na tentativa de buscar a neutralidade para que os dados da pesquisa não sejam influenciados pelo olhar do pesquisador (VIDOR, 2014). No entanto, os avanços demonstrados pela ciência ontopsicológica mostram o contrário: o pesquisador é elemento essencial da pesquisa, tendo em vista que a exatidão do 
pesquisador confere precisão aos resultados. Para isso, há a necessidade da compreensão e superação da cisão entre a ciência e o mundo da vida. Nessa compreensão, situam-se as pesquisas que utilizam o método ontopsicológico e a intervenção de um consultor com formação em Ontopsicologia, preparo técnico e com aptidão natural para a psicoterapia.

Em vista desses argumentos, as pesquisas de cunho biográfico, autobiográfico e as narrativas ou histórias de vida são apropriadas para a análise na perspectiva dos conhecimentos da Ontopsicologia, tendo-se presente a necessidade de autenticação contínua por parte do consultor e do cliente. Considera-se que a construção do conhecimento, a partir de narrativas, é um desafio, porque ele ocorre a partir de um contexto da experiência em que se toma o sujeito e o seu saber em unidades. Na autobiografia, os dados empíricos são coletados pelo próprio pesquisador, que também se torna objeto do estudo e faz uma escrita de si, e sobre si, no processo de formação. Essas pesquisas permitem produzir uma compreensão do sujeito e de sua formação por meio das narrativas de vida (LIMA; GERALDI; GERALDI; 2015).

Os estudos autobiográficos favorecem um conjunto de aprendizagens que vão muito além de um processo de conhecimento de si no registro psicológico. A escrita da narrativa da história de vida do sujeito, como momento de um processo de conhecimento da sua formação ao longo do tempo e a evidência do que está em jogo nesta escrita são os dois grandes eixos que vão organizar a reconstituição de um conjunto de reflexões, construídas a partir das observações em prol de um corpo de experiências vivenciadas (JOSSO, 2004). Para a autora, só uma visão plural de cada vida, subordinada às suas orientações fundadoras, pode ajudar o autor-pesquisador a considerar-se como um ser no mundo concreto, e não como um conjunto disperso de características ou de processos que correspondem às categorias científicas das diferentes ciências do humano, ou como um indivíduo qualquer que age unicamente por ação das forças contraditórias que o ultrapassam.

A pesquisa narrativa, como forma de entender a experiência pessoal e social, também é explicada por Clandinin e Connely (2011). Para esses autores, a construção da pesquisa narrativa deve contemplar a temporalidade, as pessoas, as ações e o contexto. No pensamento narrativo, está sempre presente o contexto, isso inclui noções do contexto temporal, espacial e outras pessoas. Em linhas gerais, este estudo caracteriza-se como uma pesquisa narrativa, de cunho autobiográfico e de abordagem qualitativa, pois lida com interpretações das realidades pessoal, familiar e empresarial do autor-pesquisador (BAUER; GASKELL, 2002; JOSSO, 2004). Assim, o corpus de análise é composto por oito narrativas, redigidas em primeira pessoa, apresentadas em itálico e enumeradas sequencialmente. 
Cabe esclarecer que as narrativas foram retiradas de Cadernos de Anotações ${ }^{2}$ do autorpesquisador, registradas no período 2007-2019. As narrativas selecionadas contêm antecedentes históricos, descrição de contextos pessoais e das empresas, relato familiar, relatos de consultoria ontopsicológica, relato de sonhos e duas entrevistas com o Acadêmico Professor Antônio Meneghetti.

\subsection{Antecedentes Históricos}

Esta seção compreende diversas passagens da vida pessoal, familiar e empresarial do autor-pesquisador, que são necessárias à compreensão do contexto autobiográfico que se pretende expor e analisar no decurso do estudo.

\subsubsection{CONTEXTO HISTÓRICO E PRIMEIRO NEGÓCIO - narrativa 1}

Nasci em Porto Alegre, primogênito de dois irmãos, filho de uma professora da rede de ensino estadual e de um chefe de escritório de cobrança. Família de origem humilde, mas com estrutura familiar dentro do padrão ético da década de 1960/70. Estudei durante todo Ensino Fundamental e Médio em escola pública, sem nunca repetir um ano e sempre aprovado por média. Aproveitava muito a vida como criança e adolescente, mas, quando a responsabilidade batia à porta, eu me dedicava muito e sempre alcançava os resultados desejados.

Após o Ensino Médio, frequentei, por um ano, cursinho pré-vestibular privado. Estudava 12 horas diárias, incluindo finais de semanas e feriados. Consegui ali minha base cultural para passar no vestibular, curso de Engenharia Civil, na Universidade Federal do Rio Grande do Sul (UFRGS), pois era minha única opção em função da falta de recursos para uma universidade privada.

Iniciei o curso superior com 18 anos, recém-completados, e com o desafio de uma greve geral dos professores já no primeiro semestre, o que me prejudicaria provavelmente na conclusão do curso.

\footnotetext{
${ }^{2}$ O autor-pesquisador, registrou suas percepções em 11 Cadernos de Anotação, no período de 2007-2019. Desses, 8 cadernos são relativos às anotações de sonhos e resumo das atividades pessoais e profissionais do dia anterior, seguidos da análise onírica com suas respectivas diretivas durante as consultorias de autenticação. Os demais Cadernos (3) referem-se às anotações dos Cursos e Residences Ontopsicológicos realizados, com registro de sonhos e interpretações em entrevistas abertas e principais pontos de compreensão do conteúdo exposto durante o Residence e as decisões de mudança pessoal e profissional e/ou fase de crises com a consequente metanoia. Os Cadernos citados são, portanto, registros sistemáticos e constituem em fonte de pesquisa.
} 
Saber Humano, ISSN 2446-6298, V. 9, n. 14, p. 6-28 Jan./Jun. 2019.

Nas férias de verão, aos 19 anos, fui trabalhar na videolocadora de um tio empresário (irmão da mãe) na cidade de Curitiba, para um ganho extra e também estava curioso para aprender como ele produzia riqueza neste novíssimo ramo de negócios, no ano de 1986.

Em três meses, aprendi o oficio e lógica básica do negócio de videolocadora e propus ao tio empresário que me desse a oportunidade de ser seu sócio em Porto Alegre. Este aceitou com a seguinte condição: investiria 200 fitas VHS de filmes e eu estruturaria uma loja com mobiliário e trabalharia lá como empreendedor junto ao irmão mais novo dele e, se tudo desse certo, a nova empresa pagaria o investimento das 200 fitas e nos tornaríamos sócios, meio e meio.

Assim, iniciei meu primeiro negócio, aos 19 anos, sem nenhum capital, apenas utilizando os meios disponíveis e relacionamento de confiança com meus familiares. Meu pai foi contra, inicialmente, pois me alertava que eu não conseguiria conduzir um negócio concomitante com a universidade e que acabaria por não concluir os estudos. Nisto, ele estava certo, pois abandonei, no $4^{o}$ ano, a Engenharia Civil para me dedicar exclusivamente aos negócios.

Trabalhei com afinco durante 4 anos neste negócio, todos os dias, sem férias, prosperando e ampliando com a abertura de uma filial, tendo, assim, meus primeiros 20 funcionários e uma gerente já no ano de 1990. Neste período, além de casar, nasceu minha única filha, aos 23 anos.

Logo, percebi que o ramo de videolocadora estava ficando saturado em função da abertura de muitos concorrentes. Fui convidado para entrar, como sócio, numa distribuidora de filmes em São Paulo, pois havia muita procura pela grande demanda de ampliação do ramo.

Nessa narrativa, o autor-pesquisador refere-se ao contexto de sua família, de origem modesta, de modo tranquilo e sem traumas. Evidencia-se também uma postura própria de um jovem esforçado e comprometido com o trabalho. Lembrando as características da Psicologia da genitura, onde a ordem de nascimento na família determina certo modo de reação frente ao mundo, identifica-se que o autor-pesquisador já apresenta delineadas as tendências psicológicas do primogênito. De acordo com Meneghetti (2011), deve ser esclarecido que, quando se fala de Psicologia da genitura, entende-se referir sempre ao gênero, não diz respeito à ordem de nascimento biológico, mas tão somente à identidade do sexo.

O primogênito psicológico espontaneamente é levado a ser chefe. No perigo, quer ser o primeiro a proteger os outros. Em outras situações, quer ser o primeiro para comandar, porque imagina ser como o primeiro pai na família, portanto tem uma tendência prepotente, generosa, mas também ingênua" (MENEGHETTI, 2011, p. 75).

Desde cedo, então, afirma-se a intencionalidade de liderança do jovem empresário. Essa constatação encontra respaldo teórico em Meneghetti (2010a, p. 33-34), "qualquer sujeito que faça movimento de deslocamento e crescimento de meios no e para o civil 
humano, é um pequeno ou grande líder. Portanto, não somente personagens merecidamente famosos (sempre conexos a variáveis econômicas), mas também empreendedores de pequenas empresas, construtores, mestres artesãos [...], etc." $\mathrm{O}$ autor pontua que "a característica comum a esses líderes se embasa em três aspectos: a) produção de postos de trabalho; b) produção de dinheiro; c) produção de qualidade" (p. 34).

\subsubsection{MUDANÇA DE NEGÓCIOS E NOVA VIDA EM SÃO PAULO - narrativa 2}

Após minha separação aos 24 anos, - mas retomaria o casamento dois anos depois-, mudei-me para São Paulo. Suspendi a matrícula na universidade e, durante dois anos, morei e trabalhei lá, dirigindo a distribuidora de vídeos, mas o ramo começou a ter muita inadimplência, oriunda do fornecimento a novos empreendedores do ramo sem experiência e com enorme concorrência, o que me levaria ao primeiro insucesso empresarial, com um pedido de falência da empresa. Após muita luta, consegui reverter o pedido de falência, pagar todos os fornecedores e fechar a distribuidora, pagando todos os funcionários entre 1990 a 1992.

O trancamento temporário da matrícula no curso superior, em função de novos negócios, pode ser visto como estratégia inteligente e necessária naquele momento. Também demonstra uma atitude de coragem, própria do jovem que confia em seu potencial e busca acertar na vida. A flexibilização em concluir ou não um determinado curso superior é aceita ainda hoje, tendo em vista que a formação universitária, mesmo sendo importante culturalmente, nem sempre é determinante para alcançar o sucesso profissional. Todavia, houve um momento de crise pessoal na separação conjugal e na mudança para outro estado. A falência nesse empreendimento pode ser associada também à "pressa da juventude", superficialidade, busca de resultados imediatos e imaturidade para administrar contexto existencial conflituoso, situação que pode ser caraterial ou pertinente ao jovem. Meneghetti (2013, p. 178) considera que "os erros que se fazem quando crianças ou quando adolescentes são os mesmos que são feitos quando adultos. Por exemplo, se, quando pequeno, o sujeito perdia cinco euros, quando grande perderá um milhão, selecionará os sócios da mesma forma que escolhia os amigos quando jovem, etc.” A grande importância da Ontopsicologia é que, antes do problema econômico, vê o operador psicológico, porque é a Psicologia do operador - de modo consciente ou inconsciente - que faz a autossabotagem (MENEGHETTI, 2013 p. 210). 


\subsubsection{NOVO NEGÓCIO E RETORNO A PORTO ALEGRE - narrativa 3}

Neste mesmo momento, o meu então sócio na distribuidora, que era um grande empresário do ramo de refeições convênio, $R H$ e vigilância, convidou-me para assumir a diretoria comercial da empresa de refeições convênio, em Porto Alegre, com o desafio de reestruturar uma empresa que passava por dificuldades, mas com grande potencial para se reerguer. Assim, aos 26 anos, assumi a diretoria comercial de uma empresa do ramo de refeições convênio, com 150 funcionários.

Em 4 anos de trabalho árduo, a empresa de refeições convênio saiu do patamar de faturamento de 150 mil dólares para 3,6 milhões de dólares mensais. Como prêmio acordado anteriormente, recebi $30 \%$ das cotas desta empresa. Contudo, em 1996, meu sócio majoritário não ia muito bem com seus outros dois negócios no ramo de RH e vigilância e, para não quebrar esses dois negócios em São Paulo, descapitalizou a empresa de refeições convênio, levando-a a sobreviver durante um ano até a autofalência.

Nessa narrativa, verifica-se, novamente, uma situação de perda econômica. Retomando Meneghetti (2013, p. 179), essa é uma forma mentis ${ }^{3}$, um caráter, não depende de dificuldades externas: tudo é um carma de escolhas realizadas individualmente. $\mathrm{O}$ autor explica que "[...] o carma é a consequência de uma ação errada, contraposta à virtualidade do sujeito. Os erros de comportamento determinam uma coação a repetir segundo a seleção temática do erro, isto é, segundo a especificidade do complexo. Uma relação errada implica perda de tempo e de inteligência” (MENEGHETTI, 2011, p. 175).

\subsubsection{INICIANDO DO ZERO NOVAMENTE - narrativa 4}

Em 1996, já com 30 anos, iniciando do zero novamente, abri uma corretora de seguros, atuando em todos os ramos: automóveis, vida e saúde. Logo, encontrei uma oportunidade na comercialização de planos de saúde e, em 3 anos, tornamo-nos a maior empresa de vendas do ramo no RS, com 120 vendedores porta a porta. Estes vendedores

\footnotetext{
${ }^{3}$ No papel de coordenador, de determinante, está o escopo. Ele constitui a forma mentis, o corpo, o objeto, o todo. Uma vez definido o escopo, instaura-se imediatamente o organograma da realização. Conjuntos, situações, instrumentos, pessoal, dinheiro, produção, tudo deve ser conexo e "organogramado" à unidade do escopo (MENEGHETTI, 2014, p. 122).
} 
foram contratados por meio da fundação de uma cooperativa de trabalho, que seria meu principal negócio pelos próximos 12 anos.

A cooperativa de profissionais de vendas, fundada em 1997, em 10 anos de atuação se tornou a maior do RS, com 1.200 cooperados ativos, trabalhando com 70 empresas clientes. Neste período, no ano de 1999, assumi também a representação de uma seguradora de vida de SP, para o estado do RS, e adquiri conhecimento desse novo negócio. Atuei como diretor comercial da região, onde dediquei esforços até o ano de 2003, ocasião em que a seguradora de SP sofreu intervenção da SUSEPE e teve sua liquidação publicada, deixando-me com dívidas e sem recursos.

No ano de 2005, motivado por ser a maior empresa de vendas de planos de saúde do RS, decidi fundar a T. Assistência à Saúde - um plano de saúde - agregando outros sócios para o empreendimento.

Observa-se, no empreendedor, crescimento seguido de perdas cíclicas. De acordo com Meneghetti (2013, p. 180), "no âmbito dos estereótipos, existem ciclos com cerca de cinco anos: um sujeito alcança, por exemplo, os 25/35 anos e se desencadeiam todos os âmbitos potenciais do estereótipo formado desde a infância”. Nas palavras do autor, “[...] portanto um homem que, quando jovem, fazia pequenos erros simpáticos, escolhas, etc., quando adulto, repetirá os mesmos erros, mas com consequências pesadas e vistosas” (MENEGHETTI, 2013, p. 180).

\subsubsection{PRIMEIRO CONTATO COM A CONSULTORIA ONTOPSICOLÓGICA- narrativa 5}

No ano de 2005, aos 39 anos, atuava como presidente da cooperativa de profissionais de venda, fundava um plano de saúde e entrava na sociedade de uma empresa de call center, de um cliente da cooperativa. Por indicação de um amigo, tive o primeiro contato com uma nova ciência chamada Ontopsicologia. Não percebi, na época, que seria, mais tarde, o marco divisor em minha vida - tendo acesso a uma entrevista com uma profissional consultora empresarial, que utilizava a metodologia ontopsicológica.

Neste primeiro contato, tive as primeiras evidências de que não atuava bem na minha vida, mas as resistências eram muitas, levando-me a duvidar da profissional e do método.

Hoje, enquanto se aplica, na consultoria empresarial, a estratégia ontopsicológica, avalia-se e verifica-se a sinalética semântica e onírica, como exposta pela fenomenologia do 
inconsciente, segundo os vetores do Em Si ôntico e, sabendo distingui-las das interferências do monitor de deflexão, não somente se tem a exatidão dos dados, a projeção da recuperação ou de investimento, mas também se tem a projeção da infalibilidade dos efeitos projetados (MENEGHETTI, 2013, p. 90).

Havia me associado a uma empresa de call center; no primeiro ano, tivemos um relativo sucesso e os negócios andavam bem, mas quando estive na consultoria, após a análise de meu sonho, constatou-se que a sociedade não era funcional para mim. Relutei e não segui a constatação. Naquele ano também, havia passado por dois incidentes de alta periculosidade, um sequestro relâmpago e um assalto junto com a esposa e filha. Esta situação e a funcionalidade das relações foram questionadas com base nos sonhos. Este episódio, associado à indicação de que a sociedade de call center não era funcional para mim, com a qual também não concordava, fez-me tomar a decisão de abandonar a consultoria de autenticação.

No ano seguinte, em 2006, enfrentei, como previsto pelo sonho, dificuldades extremas: encerrar a sociedade em meio a muitas discussões e incômodos. Deixei para trás todo o capital e tempo investidos.

O fato de o autor-pesquisador simplesmente abandonar a consultoria, sem sequer externá-lo verbalmente, repete o mesmo modo como faz uma criança, quando briga com os pais, faz a sua trouxinha de roupas e muda-se para a casa dos avós. Na concepção da criança, "se vocês não me amam e não fazem como eu quero, minha avó, que me ama, fará".

Neste aspecto, observa-se que existe a dificuldade de encontrar-se com a realidade dos fatos e o autor-pesquisador lança mão da projeção para equilibrar os seus conflitos internos. Quando a projeção está em funcionamento, “o nosso comportamento responsável projeta uma exigência em modo unidirecional, descuidando de todo o restante: descarrega em si mesmo, objetivando-se no externo e sobre o outro, falsificando a concreta identidade de si mesmo. Procura e age sobre o outro, aquilo que lhe é próprio e exclusivo" (MENEGHETTI, 2010 p. 218). O método ontopsicológico, por meio da leitura das informações oníricas, possibilita saber se as disfunções dependem do ambiente ou do sujeito. A cada momento da relação diádica $^{4}$ pode-se saber onde está o erro e como resolvê-lo (MENEGHETTI, 2008, p. 220).

\footnotetext{
${ }^{4}$ Díade significa movimento a dois, no qual um movente não pode agir sem o coincidente heteromovente. Toda a vida é díade, é o movimento, o proceder da vida. Toda a realidade é tal e existe enquanto estabelecida por uma relação (MENEGHETTI, 2012a, p. 73).
} 


\subsubsection{RELATO FAMILIAR EM 2005 - narrativa 6}

No âmbito familiar, todos dependiam diretamente ou indiretamente de mim, seja por trabalho seja por dependência financeira. Meu pai e meu único irmão mais novo, há muitos anos, trabalhavam comigo, meu pai desde 1990, е теи irmão desde 1986, bem como minha esposa e a filha adolescente dependiam de mim. Isso aumentava minha responsabilidade e compromisso, pois, se eu fosse mal em meus negócios, todos sofreriam juntos.

Os conflitos pessoais no trabalho afetavam meu relacionamento direto com meu pai, mãe, irmão, esposa e filha, pois eu era o suposto "patriarca" da família e mantinha todos por perto e sob controle, seja financeira seja psicologicamente.

Nas consultorias individuais, comecei a perceber que o modelo de gestão familiar estereotipada não era funcional para mim e nem para meus familiares. Gradativamente, comecei a fazer mudanças: separação amigável da esposa e desligamento do meu pai de minha empresa.

Difícil também foi desligar meu irmão mais novo dos meus negócios, pois ele atuava como meu advogado, entretanto, chegavam com frequência autuações do MPT, fiscalização de impostos e geração de ações de cobrança.

Por meio do processo de autenticação, compreendi a psicologia da genitura, ou seja, a existência de relação estereotipada entre primogênito e segundogênito. A interferência desse estereótipo inconsciente favorecia ações contra minha pessoa e empresa, e isso se revelou por meio da análise de alguns sonhos.

Atualmente, minha relação em âmbito familiar mudou muito, pois nenhum dos familiares depende de mim ou trabalha comigo. Meu irmão exerce a advocacia de modo autônomo. Meu pai se aposentou e, hoje, vive um novo relacionamento com uma nova companheira. Minha mãe vive bem e dedica-se à família. Minha ex-esposa tem sua profissão e minha filha, formada em Psicologia, atua em sua própria clínica.

Conforme exposto anteriormente, na narrativa 1 (um), o autor-pesquisador, sendo primogênito de sua família, foi levado naturalmente a ser o chefe e suposto patriarca da própria família. Isso se evidencia mais claramente na narrativa 6 (seis). Já o segundogênito, nascendo em uma família que já havia vivido a experiência de ter um filho e, portanto, não é mais percebido como novidade, tem uma tendência crítica e antitética em relação a qualquer pessoa, desenvolvendo-se contrário ao primogênito. Dentro dele, desenvolve-se a tendência de estudar o primogênito e a colher imediatamente os seus pontos fracos: ali torna-se forte. 
Há, ainda, um outro fator, quando o segundogênito não é realizado, com frequência, busca trabalho junto ao primogênito vencedor. Aparentemente, ele ajuda-o, mas, progressivamente, o destrói (MENEGHETTI, 2011, pp. 76-77).

No fragmento do texto narrativo anterior, evidencia-se que, quando os laços familísticos ${ }^{5}$ estereotipados confundem-se com os negócios, eles geram desequilíbrios e conflitos, perde-se o discernimento e a capacidade de refletir com objetividade sobre o escopo do projeto empresarial.

Atualmente, meu relacionamento com meus familiares é mantido, na medida do possível, por laços de admiração, respeito e independência. O ponto fundamental para a mudança interior, com relação ao âmbito familiar, foi entender a causa daquela situação desarmônica para todos. Após algumas consultorias, compreendi que eu os mantinha presos a mim por uma dependência afetiva, porque eu queria ser amado por todos e, assim, eu os gratificava com cuidados exagerados e benefícios financeiros. A partir dessa compreensão, levei alguns anos para fazer as mudanças, que fui realizando, aos poucos, uma por uma, procurando o momento certo, com base na compreensão da dupla moral.

Conforme Meneghetti (2012, p. 135), em Ontopsicologia, fala-se de dupla moral no sentido de que há uma lei que é exclusiva para o sujeito e há uma lei sobre como adaptar-se aos outros, à boa norma jurídica, social e coletiva. A partir do momento em que todos jogam, essas regras devem ser observadas; mas se trata de um jogo externo, que não é a verdade íntima da pessoa. Nessa narrativa, o autor-pesquisador evidencia também que, para efetivar as mudanças externas, foi necessário compreender que a causa de determinados efeitos era psicológica. A partir dessa compreensão, variaram-se os seus efeitos, mudando, primeiro, as causas que determinavam os seus resultados externos. Esse processo é definido como metanoia, ou seja,

\footnotetext{
variação radical do comportamento para identificar a intencionalidade do Em Si ôntico; em outros termos, reorganização progressiva de todos os modelos mentais e comportamentais. A sua essência é desvestir-se continuamente do passado e constituir-se sobre a funcionalidade imediata do sujeito aqui e agora, segundo a seleção do Eu a priori. Com esse termo Eu a priori, a Ontopsicologia entende uma mudança do piloto Eu: substituir o Eu formado pela doxa, por aquele sublimado pela intencionalidade do Em si ôntico (MENEGHETTI, 2013, p. 215).
}

\subsubsection{CRISE E RETOMADA COM A CONSULTORIA ONTOPSICOLÓGICA - narrativa 7}

\footnotetext{
${ }^{55}$ Familístico: é um termo usado pelo autor para significar as relações familiares patológicas ou que geram patologia (MENEGHETTI, 2009, p. 22).
} 
Em 2007, aos 41 anos, tive minha segunda separação da primeira esposa, problemas com o MPT na fiscalização à cooperativa e não conseguia estabilizar a empresa quanto ao plano de saúde. Tive também muita dificuldade com os sócios.

Encontrando um amigo do grupo de estudos em Ontopsicologia, no aeroporto de São Paulo, ele me sugeriu retomar a consultoria de autenticação e empresarial. Com as dificuldades de uma separação e dois negócios que não estavam bem, decidi dar uma chance à minha vida e, com humildade, esforçar-me para entender a mim mesmo. Retomei, então, a consultoria de autenticação.

Neste período, em 2007, participei de um Residence Ontopsicológico e tive a oportunidade de realizar uma entrevista aberta com o Prof. Antonio Meneghetti. Após a análise de um sonho, fui orientado a vender a T. Assistência à Saúde. Seguindo a diretiva, no início de 2008, não consegui vendê-la na totalidade, mas encontrei um novo sócio e a empresa cresceu muito nesse ano, foi o melhor ano desde a sua fundação.

Em 2009, deixei a cooperativa de profissionais de vendas e decidi retomar o negócio de call center, início a E. Call Center. Também, em 2009, aos 43 anos, ingressei no MBA, o que me auxilia no entendimento das diretivas da consultoria de autenticação.

Observa-se, na narrativa 7 (sete), que, das várias fenomenologias do autorpesquisador, emergiam, como prioridade, os aspectos problemáticos, para os quais ele, sozinho, não conseguia encontrar a solução. A decisão de retomar a consultoria ontopsicológica de autenticação, que "é o processo de training, de formação, que consente ao sujeito recuperar, em consciência, o quântico de inteligência que é” (MENEGHETTI, 2013, p. 30), demonstra a necessidade de mudança, buscando sair da situação problemática, que se fazia atual. A função da consultoria de autenticação é "reencontrar o Eu a priori do sujeito para além da reflexão fictícia” (MENEGHETTI, 2010, p. 261). "O Eu a priori é o momento em que a interação do organismo entre Em Si ôntico e ambiente dá o seu reflexo de ação única, para a vantagem do indivíduo-pessoa” (MENEGHETTI, 2010, p. 258). O consultor segue o campo semântico do cliente e, lendo logicamente o verbalizado do Em Si deste, individua a ação otimal para ele ou ação especificada pelo seu Em Si ôntico (MENEGHETTI, 2010, p. 261).

\subsubsection{CONTINUIDADE DOS NEGÓGICOS - Narrativa 8}


Em 2015, aos 49 anos, troquei minhas cotas sociais da T. pelas da VH Benefícios, saindo da sociedade T. Em 2016, segui com a E. e VH.

Em 2017, aos 51 anos, em função da nova lei de terceirização, criei uma vertical para a E. no ramo do trabalho temporário, utilizando o conhecimento adquirido, quando presidente da cooperativa de profissionais de vendas. No primeiro ano, já tivemos bons resultados, originando, em 2018, uma nova empresa chamada NT Trabalho Temporário.

Em 2018, com 52 anos, terminei a especialização em Ontopsicologia e procurei solidificar a E. Call center, expandindo a E. Trabalho Temporário, agora personalizada na NT Trabalho Temporário. Neste mesmo ano, constituímos a VH Franquias e estamos trabalhando para o seu lançamento nos próximos meses de 2019.

\subsection{ENTREVISTAS COM O PROFESSOR ANTONIO MENEGHETTI}

\section{Entrevista 1}

$\mathrm{Na}$ sequência, descreve-se a entrevista aberta $^{6}$ realizada pelo Professor Antonio Meneghetti, doravante (AM), com o autor-pesquisador, doravante (AF), durante a participação em um Residence Liderístico, em Recanto Maestro, RS.

AM-Aqui estamos. Provemos.

AF - Tudo bem!

AM - O que faz, quantos anos tem, duas ou três coisas, as mesmas que eu perguntava.

AF - 41 Anos, estou divorciado há 5 meses, sou empresário, tenho 3 empresas.

$A M-O$ que o senhor produz? O que o senhor produz como empresa?

AF- Produzo serviços. Presido uma cooperativa de profissionais de vendas, a outra é uma empresa de telemarketing - de call center - e a última empresa que eu abri, no ano passado, foi um plano de saúde.

AM - Ok, na empresa, como empresário, vai bem?

$A F$ - Sim, mas com exceção da última empresa.

AM - Mas o problema, onde está?

AF - Nos sócios.

AM - Quantos sócios você tem?

AF - Tenho quatro sócios.

AM - O senhor me diz o percentual, quanto cada um tem?

$A F-25 \%$ cada um, partes iguais.

\footnotetext{
${ }^{6}$ A entrevista foi realizada em 13 de outubro de 2007, encontra-se gravada em vídeos e pertence ao acervo da Fundação Antonio Meneghetti, que cedeu as informações para este estudo.
} 
AM - Hum, difícil, difícil, quatro. Que tipo de dificuldade, por exemplo?

AF - Nós começamos o empreendimento do plano de saúde no ano passado, dois sócios são investidores, eu sou o sócio que cuida da área comercial e tem outro sócio que cuida da área técnica, ele é um atuário, que faz os cálculos estatísticos. Dois sócios estavam brigando muito, um capitalista e o outro que é o atuário. O capitalista é o que detém, hoje, o relacionamento com o mercado, para podermos entrar no mercado, então são dois sócios importantes dentro do negócio.

AM-Certo.

AF-Eles começaram a brigar muito no início deste ano e eu era o mediador entre os dois, ficava tentando segurar os dois sócios, um reclamava do outro para mim e, no final, nem se falavam mais. No mês passado, nós quase terminamos a sociedade, quase dissolvemos a empresa. O sócio atuário resolveu sair e eu continuo, então, com os outros dois sócios.

AM - Restam dois capitalistas e o senhor. Então, vocês são em três?

AF - Minha dúvida é se eu devo permanecer com os outros sócios, se devo tentar tocar sozinho o empreendimento, arranjar uma maneira, ou também sair do empreendimento.

AM - Mas, eles capitalizam, o senhor trabalha... O senhor tem dinheiro para fazer sozinho?

$A F-N a ̃ o$, não tenho dinheiro para tocar o projeto sozinho.

AM - Para tocar o projeto sozinho é preciso do dinheiro, não? Dos dois capitalistas, um é preciso.

AF- Certo.

AM - Enquanto havia os dois que brigavam, entendo o problema, mas agora qual é o problema? As cotas como estão? 25\%-25\%, como estão as cotas agora?

AF - As cotas ficaram em três partes, em $33 \%$ para cada um.

AM - Porque agora vocês estão em três.

AF-Mas houve muito desgaste no último mês em função desta dissolução e um deles, que tem relacionamento com o mercado, também está disposto a sair da sociedade por ter se incomodado muito. Ele é empresário em outros negócios e estamos numa fase exatamente de saber se vamos os três tocar ou se ficam só dois. Se sair o outro sócio, que tem o relacionamento, estamos num ponto bem crítico da sociedade: se vamos parar a sociedade ou se vamos dar seguimento a ela.

AM - Sonho. Eu, meu parecer já tenho, hein? Sem que precise dizer.

AF- Tive um sonho em que estava visitando um dono de um banco e subia até a cobertura, mas tinha bastante dificuldade de chegar nele, em função das secretárias e seguranças, mas 
eu consegui chegar na cobertura do edifício, onde ele fica, no último andar, eu me vejo bem vestido de terno, porém estou de pés descalços.

AM - Ok, basta. Fechem a empresa. Os motivos racionais são estes: os dois capitalistas, aquele que dá a passagem ao mercado está em crise, não está convicto, um só que trabalha e dois capitalistas, se ele já está assim... Se o trabalho aumentou, se houve dificuldades de despesas porque um dos colaboradores se foi, ou seja, diminuiu quem trabalhava, quem produzia, é lógico fechar a empresa ou vendê-la. Porque o capitalista, que também dava a passagem ao mercado, se vai, é claro que ele tira a passagem para o mercado desta empresa e irá trabalhar com outra e, portanto, existirá uma depressão. Então, eu aconselho entrarem em acordo entre vocês, cada um pega a sua parte e fechar, ou vendam.

AF - Fechar ou vender.

AM - O sonho confirma isto. Basta assim. De todo modo, façam como eu disse. AF-Obrigado.

\subsubsection{FATOS E ACONTECIMENTOS APÓS ENTREVISTA COM O PROF. ANTONIO MENEGHETTI: NARRATIVA}

No princípio, levei alguns dias para assimilar a informação do Professor AM, mas, como vi que as dificuldades somente aumentariam dali para frente, reuni-me com os outros dois sócios para uma avaliação da empresa, com o objetivo de fechá-la ou vendê-la. Se fôssemos fechar, teríamos algumas despesas a mais e perderíamos dois importantes ativos da empresa, que eram um software bem customizado ao negócio e a autorização do governo para atuar no mercado de plano de saúde, concessão muito difícil de obter. Portanto, esses ativos teriam um bom valor comercial para um possivel interessado; assim, consegui convencer meus sócios a encontrarmos um comprador para a empresa.

Partimos para análise de mercado com o objetivo de encontrar um comprador. Eis que, em janeiro do ano seguinte, identificamos uma grande empresa que operava no ramo de cartões de desconto de saúde e conseguimos o acesso a seu presidente. Agendada a reunião, fizemos uma exposição dos nossos ativos, software, autorização do governo para operar no ramo de plano de saúde e um projeto bem arrojado de vendas. Em cerca de meia dúzia de reuniões posteriores, conseguimos negociar e vender $70 \%$ da empresa, mantendo-nos com $10 \%$ para cada um dos três sócios.

Com a entrada deste novo sócio/empresa, conseguimos lastro financeiro $e$ demonstração perante o mercado de participar de um grupo econômico forte e renomado, o 
Saber Humano, ISSN 2446-6298, V. 9, n. 14, p. 6-28 Jan./Jun. 2019.

que possibilitou nosso primeiro grande contrato com o governo estadual e fez com que a empresa faturasse, neste mesmo ano, 15 milhões de reais, com uma boa margem de lucro.

A orientação do Professor AM foi bem clara: vender ou fechar. Na época, vendi parcialmente a empresa, me mantendo como sócio minoritário e atuante na área comercial e foi um modo de realizar a transição para a diretiva dada pelo Professor Meneghetti. Participei desta empresa até fevereiro de 2016, vendendo, então, minhas cotas ao sócio investidor inicial. Atualmente, a empresa é líder no mercado onde atua, tem um faturamento na casa dos 50 milhões de reais anuais, com boa margem de lucro e com perspectivas de crescimento. Nesta empresa, continuo como parceiro comercial para outros negócios.

\section{Entrevista 2}

Entrevista $^{7}$ realizada em 11 de março de 2012, em Recanto Maestro.

Na entrevista, o Professor AM me pediu para relatar minha situação como empresário. Citei a ele que estava à frente dos negócios Cooperativa de profissionais de vendas, T., E. Call Center e VH Benefícios. Relatei sobre meu primeiro negócio, aos 19 anos, a primeira quebra da empresa de refeições convênios, aos 30 anos, e a situação com as empresas atuais. Referi que pretendia sair da presidência da Cooperativa naquele ano, passando a gestão para o atual conselho de administração. Também expliquei que a empresa mais antiga era a T. Assistência à Saúde, com atuação desde 2007, com sede em Florianópolis e, naquele momento, apresentava algumas dificuldades com relação aos sócios e aos negócios.

Em relação a E. Call Center, empresa fundada em 2009, na ocasião, já estava consolidada e em fase de crescimento. Sobre a VH Benefícios, fundada em janeiro de 2012, mesmo ano desta entrevista, apresentava resultados promissores em função do pouco tempo de comercialização de seus produtos de seguros de acidentes pessoais e benefícios, via call center.

As três empresas, além de prestarem serviços ao mercado em geral, prestam serviços entre si, gerando uma cadeia de valor. A VH contrata serviços de saúde da T. e serviços de call center da E. Minha preocupação era com a gestão da T., por ficar em outro estado e havia uma gestão compartilhada com os outros sócios, sem a presença diária de ambos.

Relato de um sonho por $\mathrm{AF}^{8}$

\footnotetext{
${ }^{7}$ Como não há gravação em vídeo ou áudio desta entrevista, são relatadas apenas anotações pessoais da época.
} 
Caminhando pelo centro de Porto Alegre, que estava todo em construção, havia algumas casas antigas, uma cantina de vinho com fundos para uma piscina, eu estava credenciando fornecedores para a $\mathrm{VH}^{9}$.

Orientações do Professor AM:

O professor orientou para eu trazer a T. para Porto Alegre e juntar com as outras empresas num único local, em Porto Alegre; ficar disponível para observar outro core bussiness; "cortar a cabeça”, quando o monitor de deflexão entrar em ação, pois não é real, tenho que cortar uma, duas, três, dez vezes, se necessário. Perguntou sobre família, filhos e esposa, disse que meu atual relacionamento era inteligente e que deveria mantê-lo assim, ambos morando em casas separadas e com independência financeira. Disse que eu era novo, 46 anos, e que eu era capaz e que os negócios iam bem até então.

Com base nas orientações do professor Meneghetti, em 2012, aos 46 anos, decidi sair da presidência da cooperativa, seguir com a E. Call Center e fundar a VH Benefícios, empresa promissora e com a qual mais me identifico, englobando o conhecimento de vendas via call center, seguro de acidentes pessoais e benefícios, em cuja proposta estava empenhado no momento, inclusive para trazer a T. Assistência à Saúde para Porto Alegre.

\section{Resultados e discussões}

Nesta seção, narrados em primeira pessoa, pontuam-se aspectos comparativos da vida empresarial do autor-pesquisador, no período de 2007 a 2019, após decidir seriamente compreender a metodologia da ciência ontopsicológica.

Em 2007, a minha atuação como empresário constituía-se em ser sócio da empresa T. Assistência à Saúde e estávamos na fase de investimento para lançar um plano de saúde diferenciado no mercado, não havia receitas e nem pró-labore. Na mesma época, atuava como presidente da Cooperativa de Profissionais de Vendas, que estava consolidada financeiramente, em fase de crescimento e desta advinha a minha remuneração. $O$ faturamento da cooperativa era algo em torno de oito milhões de reais anuais.

\footnotetext{
${ }^{8} \mathrm{O}$ autor-pesquisador teve esse sonho no dia 10 de março de 2012, véspera da entrevista, em Porto Alegre.

${ }^{9}$ No dia anterior ao sonho, havia almoçado com o Sr. C., da empresa de seguros fornecedora e parceira da $\mathrm{VH}$ Benefícios.
} 
Atualmente, sou sócio das empresas E. Call Center, VH Benefícios, NT Trabalho Temporário e VH Franquias Ltda. O somatório do faturamento dessas empresas chegou a 52 milhões de reais, no ano de 2018.

De 2007 a 2019, continuo atuando com gestão de pessoas, saúde e vendas. O que se alterou foram as empresas e, principalmente, a forma de atuar nos negócios, cuja mudança foi se delineando com o passar dos anos, com as consultorias de autenticação e consequente análise dos sonhos.

Assim como fazia em 2007, atendo a várias empresas clientes e a pessoas físicas. A principal mudança foi a qualidade dos meus negócios, apesar de empreender num país economicamente instável e com a classificação de segurança jurídica muito baixa, percebo que os meus negócios estão mais estáveis e com oportunidades de ampliação, tanto dos atuais como da implementação de novos empreendimentos.

Analisando, hoje, a mudança ocorreu na minha "forma mentis" como empresário e essa mudança foi realmente radical, pois o modo como penso e como atuo dentro de minhas empresas mudou significativamente para melhor, na medida em que comecei a compreender as atitudes não funcionais em relação às empresas. E, aos poucos, fui mudando para atitudes mais funcionais e os resultados positivos foram se revelando. Quando relembro do jovem empreendedor, aos 19 anos, percebo que não planejei e nem desejei ser empreendedor, simplesmente aconteceu de forma natural. Tinha muita vontade de vencer e lutei com muita força, abdicando de muitas coisas para um jovem. Mesmo com todas as dificuldades da idade e do início da carreira empresarial, havia algo forte dentro de mim que já me tornava internamente realizador e empreendedor. Interessante é que esse sentimento não passou com o decorrer dos anos, eu ainda percebo-o forte em mim, hoje, como no início, e sempre projeta no íntimo a sensação de realização atual e futura, como algo certo a acontecer, e somente o tempo e o trabalho separam-me desse inevitável sucesso. Com o estudo da obra Psicologia do Líder, comecei a compreender que essa sensação interna pode ser chamada de Em Si Ôntico definido, por Meneghetti (2013, p. 87), como "Princípio formal e inteligente que faz autóctise histórica".

Anteriormente à consultoria ontopsicológica, envolvia-me facilmente em feelings, modelo aprendido desde meu primeiro negócio, aos 19 anos, com meu tio empresário. Na época, era corriqueiro que patrões se envolvessem afetiva ou sexualmente com colaboradores. Até conhecer a consultoria de autenticação, atuava nesse modelo. Porém, em uma das entrevistas de consultoria, argumentei que este era o meu modo de atuar e que sempre ganhei dinheiro, mesmo assim. Então, foi-me colocada a seguinte questão: "Imagine se você não 
tivesse este comportamento, quanto dinheiro teria ganho a mais, ou quanto não teria perdido". Esse questionamento, sem viés moral e sem julgamento, mas como ótica de resultado nos negócios, deixou-me em crise, pois, pela primeira vez, começava a refletir sobre o que realmente eu procurava como empresário.

A base teórica que complementou a minha mudança ocorreu em uma aula do grupo de estudos da consultoria ontopsicológica, no dia três de fevereiro de 2010, em que foram apresentadas as quatro esferas do líder e as suas lógicas correspondentes, conforme mostra a Figura 01 (um).

Figura 01: Representação gráfica das quatro esferas do líder.

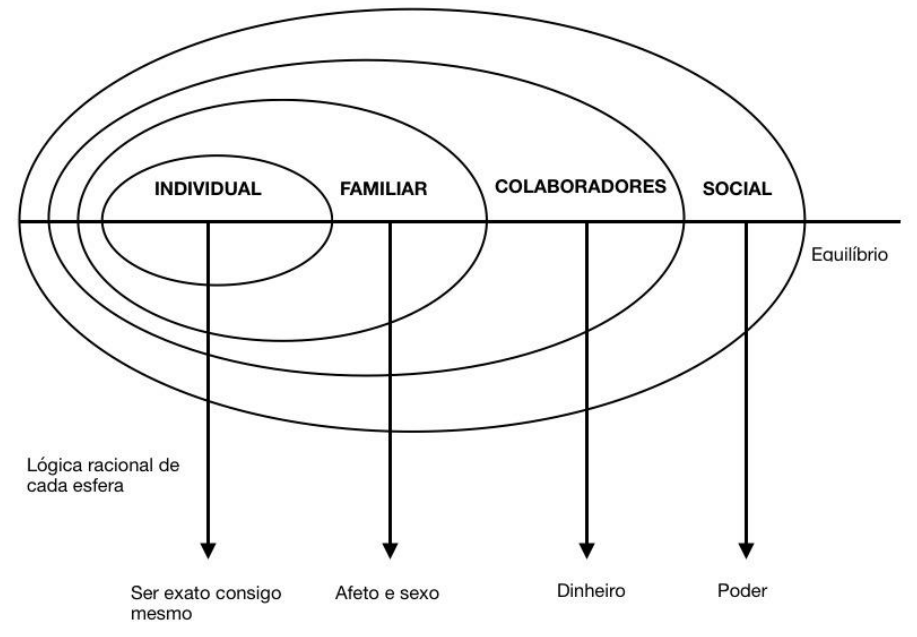

Fonte: Adaptado de Meneghetti (2013).

Compreendi a lógica de cada esfera e entendi que não é funcional misturar as lógicas, por exemplo, colocando afeto e sexo na esfera dos colaboradores ou a lógica do dinheiro na esfera familiar. Devo buscar uma proporção e harmonia nessas quatro dimensões, respeitando a lógica de cada uma delas. A esfera individual pessoal compreende o sujeito em sentido físico, absoluto de existência. A esfera afetiva é constituída pelo ambiente de referência emotiva, sexual, de amor: as suas referências de valor absoluto. A esfera dos colaboradores compreende as pessoas físicas, por meio das quais o líder opera: os mediadores de atividade econômica, legal, etc. Enfim, há a esfera social, da atividade no mundo dos negócios, do ambiente, da explícita atividade econômica: relações, diplomacia e todo o vasto mundo que a arte do líder compreende (MENEGHETTI, 2013, p. 39).

Atualmente, o meu comportamento empresarial segue a lógica do dinheiro em relação ao business, com todos os meus funcionários, e os primeiros resultados notados foram: liberdade, segurança, dignidade, sentimento de autoridade profissional, como forma de 
atuação empresarial interna na empresa, uma intrínseca honestidade comigo e com o corpo de colaboradores. O poder de atuação empresarial, sem ser refém de qualquer psicologia distinta do business, faz-me sentir honesto e íntegro, sem elementos alheios ao negócio, respeito a todos os colaboradores, sem comportamentos que se desviem do negócio. O envolvimento anterior com outras lógicas fora do business gerava agressividade reativa por parte de corpo colaborativo.

Como consequência, é inegável que houve uma melhora nos resultados empresariais, financeiros e de consolidação de novos negócios. Nas palavras de Meneghetti (2013), o líder tem que ser sempre o modelo funcional para o business, ainda que alguns não entendam.

Outro ponto fundamental foi a percepção de responsabilidade com as empresas em que atuo, ocorrida em um Residence em Recanto Maestro, em outubro de 2011. Com as colocações da consultora que conduzia o Residence, percebi que sou uma pessoa em função para a empresa e não o contrário. Entendi que a empresa é um corpo social criado por mim, mas não para mim. Eu não posso fazer o que eu bem entender com ela, de modo infantil e possessivo, pois a empresa é um efeito das virtudes e dons que eu tenho e que me possibilitaram construí-la, isto é, são virtudes e dons da vida, pelos quais tenho que zelar com minha atuação digna e profissional. Meneghetti (2013) cita que o empresário é um bem social.

Em outra oportunidade, durante um Residence no Recanto Maestro, em abril de 2015, percebi que o meu estereótipo dominante era: Quero ser amado! Muitas vezes entrava em negócios ou aceitava clientes com o escopo de agradar, ou seja, queria o primado do afeto, do bom menino, do salvador, do herói e queria ser gratificado com a aceitação e o reconhecimento dos outros, sem colocar em primeiro lugar a relação de funcionalidade do negócio para a empresa e para o contratante. Anteriormente, também em um Residence em Recanto Maestro, em junho de 2009, a consultora havia comparado essa minha atitude com uma expressão utilizada no futebol: "Jogar para a torcida e não para ganhar o jogo!"

Uma empresa tem, como relação, sempre a problemática do business. Outro ponto que aprendi foi não deixar o problema entrar em mim, não me deixar consumir por ele, mas entrar no problema e resolvê-lo, se não for assim, ficaria objetificado pelo problema, perdendo a inteligência inata que contém a solução. Para essa realidade, esclarece Meneghetti (2013),

no problema, então, deve-se permanecer só frio, materialista, devendo-se analisá-lo de modo técnico, sem investimento passional. Uma vez decidido, são necessários alguns conhecimentos, é necessário o advogado adequado, o contador expert sobre aquela questão, sobre aquele trabalho, isto é, se não se sabe, é possível buscar conselho técnico, mas não um conselho sobre como resolver o problema; o sujeito deve chegar sozinho ao modo de resolvê-lo (MENEGHETTI, 2013, p. 181). 
A relação com o medo foi outra grande mudança que ocorreu no processo de autenticação. Não é fácil empreender e conduzir uma empresa sem que a presença do incerto manifeste-se com o sentimento do medo. Comecei a compreender o que era esse medo, mesmo quando se pensa em questões financeiras ou bancárias, e percebi que, em 99\% das vezes, o medo sentido não correspondia a um perigo real. Era um medo fantasmagórico, paralisador, congelante e provocador de muita angústia e, mesmo não tendo uma causa real, o seu efeito no corpo era real. Para mim, na novidade de um problema ou na ameaça de grandes dificuldades, o medo sempre faz-se presente e a primeira reação organísmica é o desconforto intestinal.

Esse aspecto também foi aprendida em consultoria, isto é, que a inteligência do corpo informa por meio da variação organísmica. Então, tem-se à disposição a metodologia ontopsicológica para verificar se aquele medo tem uma causa real ou se é apenas o efeito do monitor de deflexão (MDD) ${ }^{10}$, que causa sempre três efeitos: medo, culpa e sensação de sujeira. Conforme Meneghetti (2012, p. 179), "para evitar os efeitos do MDD, deve-se desviar o pensamento e distrair-se com algo funcional".

\section{Considerações finais}

Procurando responder ao problema de pesquisa levantado neste estudo, propôs-se, como objetivo, analisar as contribuições da consultoria ontopsicológica nas esferas pessoal, familiar e de liderança empresarial do autor-pesquisador. A análise realizada permitiu a elaboração das considerações a seguir, em primeira pessoa.

$\mathrm{Na}$ esfera pessoal, a consultoria ontopsicológica propiciou o entendimento do nascimento contínuo do $\mathrm{Eu}$, até chegar à Pessoa ${ }^{11}$. Compreendi que, no momento em que fico atento às motivações que me levam a executar uma ação, posso decidir se a executo ou não, em função da variação da percepção organísmica, que me indica, no momento exato, a decisão otimal, isto é, tomo a melhor decisão em conformidade com minha identidade ${ }^{12}$.

Anteriormente, quando surgia uma motivação qualquer para mim, na maioria das vezes, executava-a como se estivesse num piloto automático. Atualmente, consigo, em boa parte das situações, parar e revisar a ação com a ausculta organísmica ou com a simples

\footnotetext{
${ }^{10}$ Monitor de deflexão - Uma das três descobertas da ciência ontopsicológica. Engenho psicodélico deformador das projeções do real à imagem (MENEGHETTI, 2012, p. 175).

${ }^{11}$ Pessoa, do "Lat. per se esse" = ser por si. (MENEGHETTI, 2012a, p. 211).

${ }^{12}$ Identidade, do "Lat. id quod est ens" = o que o ser é aqui, assim e agora (MENEGHETTI, 2012a, p. 130).
} 
pergunta: Essa motivação-informação é minha? O aprendizado, nas consultorias, para verificar continuamente as muitas informações que recebemos e que não são nossas, mas que tendemos a aceitar como próprias, revolucionou o meu modo de pensar e, por consequência, os meus atos. Destaco que o estudo do campo semântico e o aprendizado de sua leitura trouxe-me uma novidade de percepção sobre o mundo e o modo como atuo no cotidiano. Mesmo sendo um aprendiz dessa descoberta da Ontopsicologia, entendo melhor o significado da regra beneditina, definida por São Bento, "ora et labora": vigie e trabalhe (MENEGHETTI, 2010b).

$\mathrm{Na}$ esfera familiar, a consultoria ontopsicológica possibilitou a compreensão da causa das relações desarmônicas no grupo familiar. Após algumas consultorias, compreendi ser uma necessidade minha manter pais, irmão, companheira e filha em dependência econômica e afetiva. Em outras palavras, queria ser amado por todos e, assim, gratificava-os com cuidados exagerados e benefícios financeiros. Essa compreensão levou alguns anos, cujas mudanças fui realizando aos poucos, uma por uma e, no momento certo, sem causar danos de relacionamento ou dificuldades estruturais.

$\mathrm{Na}$ esfera empresarial, a maior mudança foi a compreensão da responsabilidade de gerir os dons que a vida concedeu-me, ou seja, meu core business, que é a arte de liderar para prestar serviços. Esse entendimento de responsabilidade, quando atuado dentro das minhas capacidades e competência, traz um vislumbre de uma outra compreensão, em fase de assimilação, que é a liberdade. Meneghetti, no livro Isomaster, declara que "chega-se a um ponto em que esta liberdade é exclusiva arte. A arte é aquela dimensão onde a mente não tem mais dificuldade de meios, portanto, pode fazer e formalizar aquilo que lhe agrada. É uma dimensão natural da racionalidade do Em Si ôntico" (2018, p. 18). O autor prossegue explicando que "a arte é dimensão imprescindível à qual se chega, inevitavelmente, após um tirocínio existencial de sucesso" (MENEGHETTI, 2018, p. 18). O autor não se refere apenas à liberdade espiritual, mas também a uma liberdade de sabedoria relacionada à liberdade econômica, legal, terrena. Com isso, “[...] se começa a viver o mundo segundo o próprio humor, segundo as próprias estações e não segundo constrições" (MENEGHETTI, 2018, p. 18).

Quando li essa passagem relativa à liberdade, segundo o Prof. Antonio Meneghetti, meu corpo inteiro vibrou e minha alma pacificou-se, tendo evidenciado que é possível à liberdade graças à metodologia ontopsicológica, que consente a infalibilidade racional. Em nota de rodapé, no livro Isomaster, encontra-se a seguinte explicação a respeito da metodologia ontopsicológica: “Trata-se de uma técnica superior de compreender a simples 
evidência entre o Eu lógico-histórico e o Em Si ôntico. Quem tem esta evidência é livre e imune às constrições, riscos, medos, esperanças que todos vivem” (MENEGHETTI, 2018 p. 18).

Portanto, os relatos apresentados e analisados neste estudo exemplificam que, quando a intervenção ontopsicológica é realizada de maneira correta, com a pré-disposição do cliente, os resultados evidenciam-se em todas as esferas, pessoal, social, empresarial. O estudo também comprova a eficácia da consultoria empresarial, com orientação ontopsicológica, distinguindo-a das demais abordagens tradicionais de consultoria, tendo em vista que atua na unidade base do ser humano e não somente nas esferas operacionais de uma empresa.

\section{Referências}

BAUER, W; GASKELL, G. Pesquisa qualitativa com texto: imagem e som: um manual prático. Petrópolis, RJ: Vozes, 2002.

CERATTI, E.; RODEGHERI, V. L. A formação do líder e a consultoria ontopsicológica: um estudo autobiográfico. In: FUNDAÇÃO ANTONIO MENENGHETTI (Org.). Ontopsicologia: ciência interdisicplinar. v.1I. Recanto Maestro, São João do Polesine, RS: Fundação Antonio Meneghetti, 2016. pp. 393-442.

CLANDININ, D. J.; CONNELlY, F. M. Pesquisa narrativa: experiências e histórias na pesquisa qualitativa. Uberlândia, MG: EDUFU, 2011.

JOSSO, M. C. Experiências de vida e formação. São Paulo: Cortez, 2004.

LIMA, M. E. C. de C.; GERALDI, C, M. G.; GERALDI, J. W. O trabalho com narrativas na investigação em educação. Educação em Revista. Belo Horizonte, v. 32, n. 1, pp. 17-44, jan./mar., 2015.

MENEGHETTI, A. Manual de Ontopsicologia. 4. ed. Recanto Maestro, RS: Ontopsicológica Editrice, 2010a.

MENEGHETTI, A. Arte, sonho e sociedade. Recanto Maestro, RS: Ontopsicológica Editrice, 2010b.

MENEGHETTI, A. O projeto homem. 3. ed. Recanto Maestro, RS: Ontopsicológica Editrice, 2011.

MENEGHETTI, A. Dicionário de Ontopsicologia. 2. ed. rev. atual. Recanto Maestro, RS: Ontopsicológica Editora Universitária, 2012a.

MENEGHETTI, A. A arte de viver dos sábios. 4. ed. Recanto Maestro, RS: Ontopsicológica Editrice, 2012b.

MENEGHETTI, A. Psicologia empresarial. São Paulo, SP: FOIL, 2013a. 
.MENEGHETTI, A. A psicologia do líder. 4. ed. Recanto Maestro, RS: Ontopsicológica Editrice, 2013b.

MENEGHETTI, A. Os jovens e a ética ôntica. Recanto Maestro, RS: Ontopsicológica Editrice, 2013c.

MENEGHETTI, A. A crise das democracias contemporâneas. Recanto Maestro, RS: Ontopsicológica Editrice, 2014.

MENEGHETTI, A. Racionalidade Ontológica. Recanto Maestro: Ontopsicológica Editora Universitária, 2015.

MENEGHETTI, A. Isomaster, um ensaio sobre a infalibilidade econômica. 2. ed. Recanto Maestro, RS: Fundação Antônio Meneghetti, 2018.

PETRY, A. A consultoria Ontopsicológica empresarial: uma abordagem humanista às organizações. In: FUNDAÇÃO ANTONIO MENENGHETTI (Org). Ontopsicologia: ciência interdisicplinar. V.1. Recanto Maestro, São João do Polêsine,RS: Fundação Antonio Meneghetti, 2015. pp. 59-102.

SPEROTO, I. F. Mulher e liderança: uma narrativa autobiográfica. Saber Humano, Recanto Maestro, v.7, n.10, pp. 53-75, 2017.

VIDOR, A. Fenomenologia e ontiopsicologia: de Husserl a Meneghetti. Recanto Maestro, RS: Ontopsicológica Editora Universitária, 2013.

VIDOR, A. Opinião ou ciência: tecnologia X vida. Recanto Maestro, RS: Ontopsicológica Editora Universitária, 2014. 